
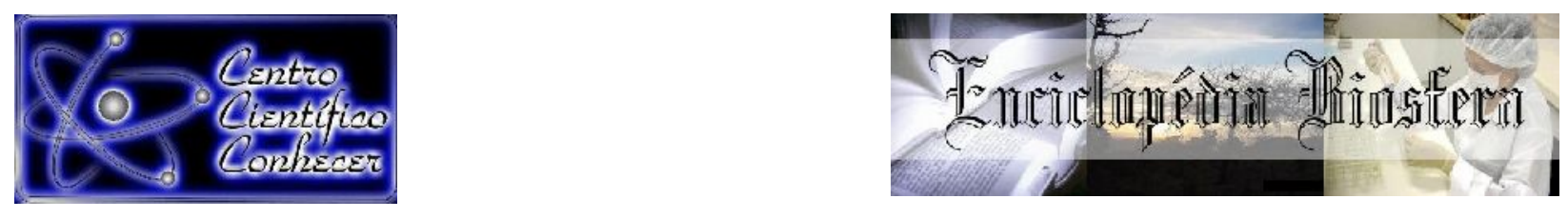

\title{
ASPECTOS REPRODUTIVO DE Theobroma speciosum EM UMA POPULAÇÃO NATURAL NO NORTE DE MATO GROSSO
}

Tatiane Lemos Varella ${ }^{1}$, Auana Vicente Tiago ${ }^{2}$, Fernando Saragosa Rossi ${ }^{3}$, Viviane Martins ${ }^{4}$, Ana Aparecida Bandini Rossi ${ }^{5}$

${ }^{1}$ Bióloga, Mestre em Genética e Melhoramento de Plantas, Universidade do Estado de Mato Grosso, Campus de Alta Floresta, MT, Brasil.

2Doutoranda em Biodiversidade e Biotecnologia da Amazônia Legal, PPGBionorte, Universidade do Estado de Mato Grosso, Campus de Alta Floresta, MT, Brasil. Email: auana_bio@hotmail.com

${ }^{3}$ Mestrando em Biodiversidade e Agroecossistemas Amazônicos, PPGBioAgro, Universidade do Estado de Mato Grosso, Campus de Alta Floresta, MT, Brasil.

${ }^{4}$ Bióloga, Universidade do Estado de Mato Grosso, Campus de Alta Floresta, MT, Brasil.

${ }^{5}$ Professora adjunta da Faculdade de Ciências Biológicas e Agrárias, Universidade do Estado de Mato Grosso, Campus de Alta Floresta, MT, Brasil.

\section{Recebido em: 06/04/2019 - Aprovado em: 10/06/2019 - Publicado em: 30/06/2019} DOI: 10.18677/EnciBio_2019A201

\begin{abstract}
RESUMO
O gênero Theobroma, encontrado na região amazônica, é composto por 22 espécies, na qual são constantemente ameaçadas pela fragmentação florestal e exigem estratégias de conservação e manejo, visando preservá-las e utilizá-las em futuros programas de melhoramento genético. Objetivou-se com este estudo avaliar aspectos reprodutivos de Theobroma speciosum., por meio da viabilidade polínica e receptividade estigmática em indivíduos nativos da floresta Amazônica. A pesquisa foi realizada na cidade de Alta Floresta, MT. Botões florais e flores abertas foram coletados para análise da receptividade do estigma e viabilidade polínica. Para estimar a viabilidade polínica, utilizou-se um mix de polens para cada um dos horários estabelecidos. A receptividade do estigma foi avaliada com peróxido de hidrogênio a 3\%, baseada na intensidade de formação de bolhas na superfície do estigma. A abertura das flores iniciou-se às $02 \mathrm{~h}$ apresentando flores completamente abertas após as 06h. A viabilidade polínica permaneceu alta, independente do horário de coleta analisado, com média superior a $94 \%$. Os estigmas de $T$. speciosum, encontraram-se receptivos em todos os horários de avaliação, com percentual médio acima de $75 \%$ de receptividade, entretanto os horários das $2 \mathrm{~h}$ e $10 \mathrm{~h}$ apresentaram as maiores taxas, com média de 95\%. Assim, recomenda-se, que as polinizações controladas sejam realizadas entre as $2 \mathrm{~h}$ e $10 \mathrm{~h}$, período de maior receptividade estigmática e maior disponibilidade de pólen nas flores.
\end{abstract}

PALAVRAS-CHAVE: Amazônia, conservação, melhoramento vegetal. 


\title{
REPRODUCTIVE ASPECTS OF Theobroma speciosum IN A NATURAL POPULATION IN THE NORTH OF MATO GROSSO
}

\begin{abstract}
The genus Theobroma, found in the Amazon region, is composed of 22 species, in which they are constantly threatened by forest fragmentation and require conservation and management strategies, in order to preserve them and use them in future breeding programs. The objective of this study was to evaluate reproductive aspects of Theobroma speciosum through pollen viability and stigmatic receptivity in native individuals of the Amazon forest. The study was carried in the city of Alta Floresta, MT. Floral buds and open flowers were collected to analyze stigma receptivity and pollen viability. To estimate the pollen viability through Alexander reactive dye, a mix of pollen was used for each of the established schedules. Stigmatic receptivity was evaluated with $3 \%$ hydrogen peroxide, based on the intensity of bubble formation on the surface of the stigma. The opening of the flowers began at 02:00 p.m., showing fully opened flowers after 06h. Pollen viability remained high, regardless of the collection time analyzed, with an average of over $94 \%$. The stigmas of $T$. speciosum were receptive at all times of evaluation, with an average percentage above $75 \%$ of receptivity. However, the $2 \mathrm{~h}$ and $10 \mathrm{~h}$ hours presented the highest rates, with an average of $95 \%$. Thus, it is recommended that controlled pollinations be carried out between $2 \mathrm{~h}$ and $10 \mathrm{~h}$, period of greater stigmatic receptivity and greater availability of pollen in flowers.
\end{abstract}

KEYWORDS: Amazon, conservation, plant breeding.

\section{INTRODUÇÃO}

O gênero Theobroma pertence à família Malvaceae e possui, aproximadamente, 22 espécies, das quais 13 ocorrem no Brasil (ESTEVES, 2014), tendo como representantes mais ilustres o cacau ( $T$. cacao) e o cupuaçu ( $T$. grandiflorum), únicas espécies do gênero cultivadas comercialmente (SILVA et al., 2015).

Theobroma speciosum Willd. ex Spreng (cacauí, cacau de macaco) (FLORA DO BRASIL 2020, em construção) ainda é pouco conhecido, apesar de suas tradicionais áreas de ocorrência. Apresenta grande potencial para produzir derivados para consumo humano e pode ser encontrado em toda a região amazônica e entre as espécies do gênero (GIUSTINA et al., 2014). Seus frutos são consumidos in natura ou preparados como suco e as suas sementes são utilizadas na produção de chocolate, geralmente nas comunidades nativas da Amazônia (LORENZI, 2009). Sua floração é observada entre os meses de agosto a outubro, com amadurecimento dos frutos ocorrendo entre fevereiro a abril (LORENZI, 1998).

A fase reprodutiva é um momento importante na vida de qualquer organismo, influenciada diretamente pelas condições bióticas e abióticas, o que pode ocasionar dificuldades na germinação, no crescimento e na sobrevivência das plântulas (OTÁROLA; ROCCA, 2014; VARELLA et al., 2018). Além disso, pesquisas envolvendo a biologia reprodutiva de espécies nativas são importantes para determinar estratégias a serem adotadas em um programa de melhoramento genético e conservação (STIEHL-ALVES; MARTINS, 2008) e oferecer dados para entender os processos de domesticação dessas espécies.

Informações sobre a viabilidade do grão de pólen e a variação da receptividade estigmática são essenciais para escolha de progenitores a serem usados em casos de hibridações artificiais (STIEHL-ALVES; MARTINS, 2008; 
TAKEHANA et al., 2013; SOARES et al., 2016). O estágio floral que caracteriza a receptividade do estigma varia de espécie para espécie. Sendo assim, o estigma é caracterizado como receptivo quando é capaz de receber os grãos de pólen e promover sua germinação (CRISPIM et al., 2017).

Os métodos colorimétricos e baseados em peróxido de hidrogênio $\left(\mathrm{H}_{2} \mathrm{O}_{2}\right)$ a $3 \%$ são muito utilizados para testar a viabilidade dos polens e receptividade do estigma, como os trabalhos descritos por Arenas-de-Souza et al. (2016), Hister e Tedesco (2016), Ramos et al. (2017), Chen et al. (2018) e de Lima et al. (2018).

Diante do exposto, os estudos envolvendo o cacauí tornam-se importantes pois a espécie representa uma possível fonte de resistência entre a maioria das espécies economicamente relevantes pertencentes gênero Theobroma (SILVA et al., 2015), além do mais, essa espécie tem enfrentado pressão crescente por parte da fragmentação e exploração florestal (DARDENGO et al., 2016).

Portanto, objetivou-se com este estudo avaliar aspectos reprodutivos de Theobroma speciosum Willd. ex Spreng., por meio da viabilidade polínica e receptividade estigmática em indivíduos nativos da floresta Amazônica.

Área de estudo

\section{MATERIAL E MÉTODOS}

A coleta do material vegetal foi realizada em um fragmento florestal urbano remanescente, denominado Parque $\mathrm{C} / \mathrm{E}$, localizado no município de Alta Floresta, MT, onde a espécie Theobroma speciosum ocorre naturalmente. O Município está situado entre as coordenadas geográficas de 9o 02' 29" a 111ㅜㄱ' 45" de Latitude Sul

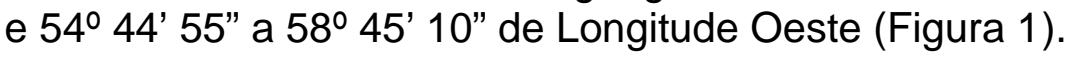

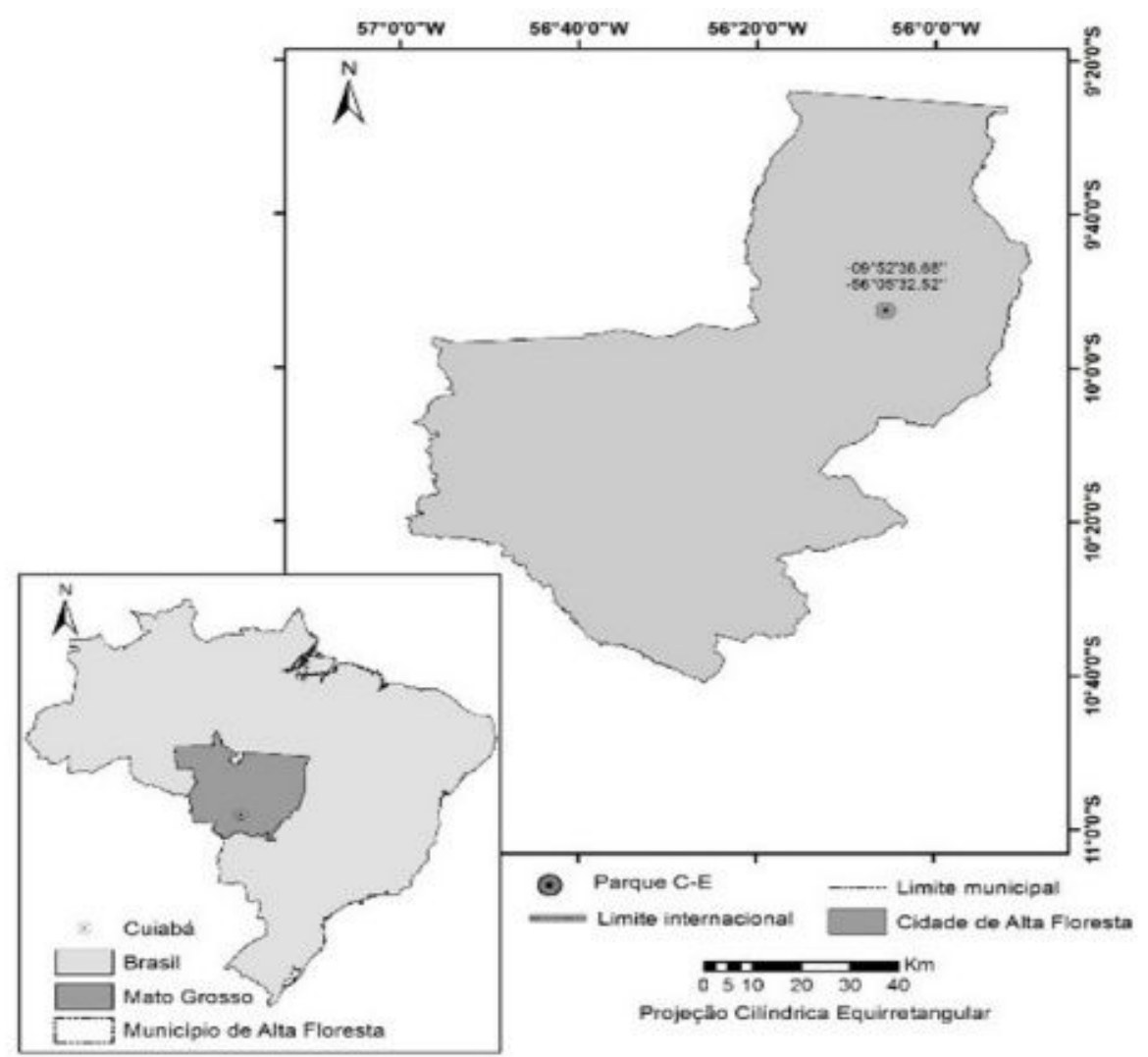

FIGURA 1- Localização do Município de Alta Floresta-MT com destaque para a área de estudo no fragmento florestal urbano C/E. Fonte: os autores. 


\section{Material Vegetal}

Para estimar a viabilidade polínica e a receptividade estigmática foram coletadas flores em antese e pré-antese. As coletas foram feitas em setembro de 2014, temporada de florescimento da espécie, em um período de $24 \mathrm{~h}$, com intervalos de $4 \mathrm{~h}$. O primeiro horário de coleta se iniciou às $22 \mathrm{~h}$, neste foram coletados apenas botões florais, e no último horário às $24 \mathrm{~h}$ após às $22 \mathrm{~h}$, flores completamente abertas.

\section{Viabilidade Polínica}

Para determinar a viabilidade polínica utilizou-se um mix de botões florais em pré-antese e antese para cada um dos horários estabelecidos. As flores coletadas foram fixadas em solução carnoy (etanol: ácido acético, na proporção 3:1), levado ao laboratório de Genética vegetal e Biologia Molecular, na Universidade do Estado de Mato Grosso - UNEMAT, Campus de Alta Floresta, MT e mantidos em temperatura ambiente por 24 horas, posteriormente, foram transferidos para álcool etílico 70\% e armazenados em freezer até o preparo das lâminas.

Para cada horário de coleta foram preparadas oito lâminas, coradas com a solução tripla de reativo de Alexander (ALEXANDER, 1980). Posteriormente, as lâminas foram observadas pelo método de varredura, sob microscópio óptico binocular com lente objetiva de 40x, e em cada lâmina contabilizados 250 grãos de pólen, perfazendo um total de 2000 grãos de pólen por horário avaliado.

Foram considerados viáveis grãos de polens que se apresentavam com tamanho normal, protoplasma corado e exina intacta, e inviáveis grãos vazios e mal formados (LIMA et al., 2018; QUEIROZ et al., 2018). Os dados foram calculados pela equação (MORENO et al., 2015):

$$
\text { Viabilidade do pólen }(\%)=\frac{n^{\circ} \text { de grãos corados }}{n^{\circ} \text { de grãos contados }} * 100
$$

Os dados obtidos foram submetidos a análise de variância e as médias comparadas pelo teste de Tukey em nível de $5 \%$ de probabilidade e analisados com o auxílio do programa GENES (CRUZ, 2013).

\section{Receptividade estigmática}

A receptividade estigmática foi observada no campo por três dias, contabilizando sete horários de avaliação como citado acima, completando um ciclo de $24 \mathrm{~h}$ de observação. Em cada horário foram analisados 10 estigmas de botões ou flores dependendo do horário de avaliação. Os estigmas foram retirados e imersos em peróxido de hidrogênio a $3 \%\left(\mathrm{H}_{2} \mathrm{O}_{2}\right)$, observado com lupa manual (10x).

A determinação da receptividade estigmática foi baseada na intensidade de formação de bolhas na superfície do estigma. Para obter resultados confiáveis, estigmas danificados ou com pólen na superfície não foram usados. Foram utilizadas cinco notas de avaliação para a receptividade, nos seguintes percentuais: 0\% (não receptivo); $25 \%$ (pouco receptivo); $50 \%$ (parcialmente receptivo); $75 \%$ (muito receptivo) e $100 \%$ (totalmente receptivo).

O efeito dos horários sob a receptividade do estigma foi observado com base no percentual médio em cada intervalo de observação e através da análise de regressão obtida com o auxílio do programa SISVAR (FERREIRA, 2008). 


\section{Biologia Floral}

\section{RESULTADOS E DISCUSSÃo}

As flores de $T$. speciosum são de coloração vermelho-púrpura, hermafroditas agrupadas em inflorescências densas e aglomeradas, que se inserem no caule desde a base (Figura 2A e B).

De acordo com Souza e Venturieri (1998) T. speciosum é uma espécie autoincompatível, com barreiras físicas entre o gineceu e o androceu, o que favorece a alogamia. Deste modo, conhecer a forma de reprodução das espécies é importante, uma vez que, além de determinar as formas de como ocorre esse processo, também pode-se indicar efeitos na colonização de diferentes habitats e sugerir respostas para alterações ambientais (SOUZA et al., 2018).

Foram identificados quatro estágios florais durante o processo de avaliação da viabilidade polínica e receptividade estigmática como demonstrado na Figura 2.

$\mathrm{O}$ primeiro estágio, onde as coletas ocorreram às $22 \mathrm{~h}$, é identificado por botões fechados em pré-antese (Figura $2 \mathrm{~A}$ ); o segundo estágio, com coletas às $02 \mathrm{~h}$, é caracterizado pela ruptura nas sépalas, ou seja, início da abertura dos botões florais (Figura 2B). Durante o terceiro e quarto estágio as flores encontraram-se semi-abertas (Figura 2C) e abertas (antese) (Figura 2D), coletadas às 06h (terceiro estágio) e 10h, 14h, 18h e 22h (quarto estágio), respectivamente.

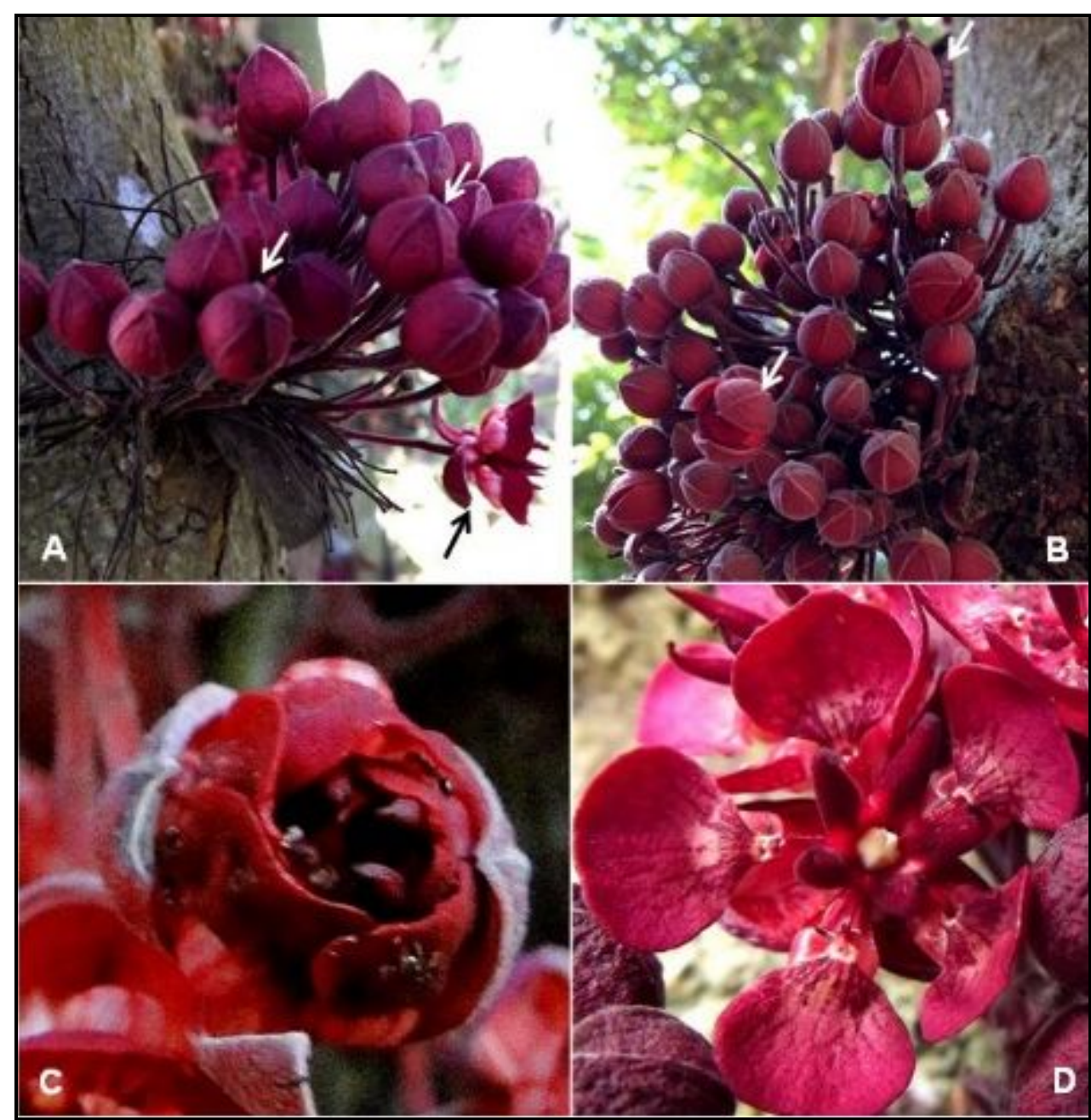

FIGURA 2-Fase de desenvolvimento floral de T. speciosum. (A) Botões fechados (seta branca) e flor aberta (seta preta); (B) Botões em pré-antese; (C) Flor semi-aberta; (D) Flor aberta. Fonte: os autores. 


\section{Viabilidade Polínica}

A análise de variância demonstrou diferenças significativas $(p<0,01)$ para a viabilidade polínica entre os horários de coleta das flores de $T$. speciosum (Tabela 1). Observa-se uma alta porcentagem de pólens viáveis (Figura $3 A$ ), com média acima de $94 \%$ independente do horário coletado, conforme Tabela 2.

TABELA 1- Resumo da Análise de variância para os sete horários avaliados de $T$. speciosum.

\begin{tabular}{cccc} 
Fontes de Variação & GL & Quadrado Médio (\%) & F \\
\hline Horários & 6 & 29,39 & $0,0^{* *}$ \\
Resíduos & 49 & 2,55 & \\
\hline C.V.(\%) & 1,64 & & \\
\hline${ }^{* *}$ significativo a 5\% de probabilidade. & &
\end{tabular}

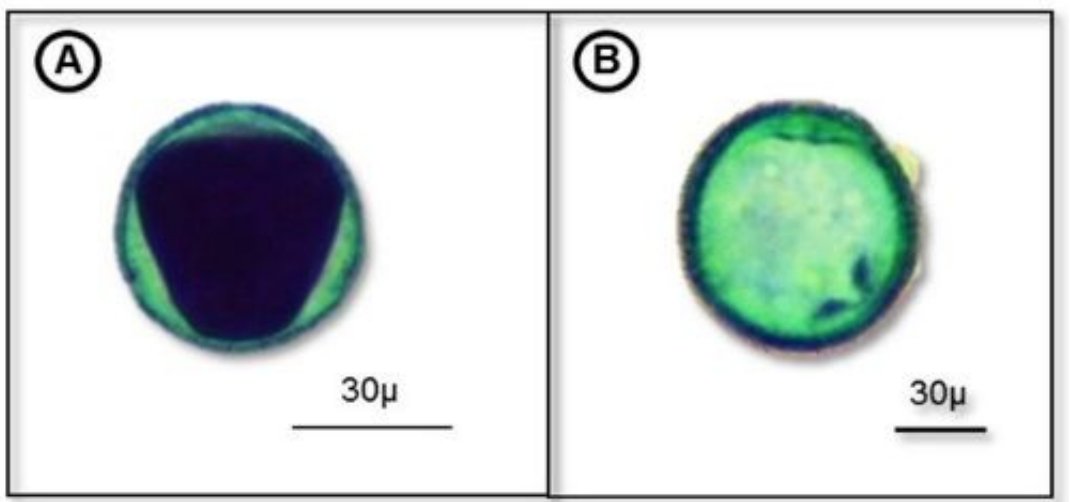

FIGURA 3- Pólens de T. speciosum corados com reativo de Alexander. Viáveis (A); inviáveis (B). Fonte: os autores.

TABELA 2- Média de grãos de polens viáveis para os sete horários observados de T. speciosum.

\begin{tabular}{ccc}
\hline Horários & Médias (\%) & C. v. (\%) \\
\hline 22h00min & $99,20 \mathrm{a}$ & 0,68 \\
02h00min & $95,30 \mathrm{~cd}$ & 1,41 \\
06h00min & $96,50 \mathrm{bc}$ & 1,19 \\
10h00min & $98,45 \mathrm{ab}$ & 1,01 \\
14h00min & $94,00 \mathrm{~d}$ & 3,66 \\
18h00min & $97,55 \mathrm{abc}$ & 0,71 \\
22h00min & $98,65 \mathrm{ab}$ & 0,99 \\
\hline
\end{tabular}

Médias seguidas pela mesma letra não diferem estatisticamente entre si pelo teste de Tukey em nível de $5 \%$ de probabilidade. C. $V$ = Coeficiente de Variação.

Arenas-de-Souza et al. (2016), estudando receptividade estigmática e viabilidade de polínica de Theobroma subincanum Mart. utilizando dos mesmos horários de coleta deste trabalho, também encontrou uma a alta viabilidade polínica ENCICLOPÉDIA BIOSFERA, Centro Científico Conhecer - Goiânia, v.16 n.29; p. 285 
em todos os tempos avaliados (> 98\%). Hister e Tedesco (2016) utilizando deste corante para estimar a viabilidade do pólen em Psidium cattleianum, obtiveram valores de superiores a $80,3 \%$, reforçando a eficiência do corante utilizado, sendo indicado o uso do reativo de Alexander na análise da viabilidade do pólen em outras espécies.

Esta alta viabilidade é um fator importante para a reprodução da espécie, pois, a produção de grãos de pólen inviáveis reduz a eficácia na polinização. Além disso, muitos grãos de polens acabam não sendo utilizados na fertilização, pois são perdidos no transporte através dos ventos ou na alimentação de insetos, dessa forma, quanto maior a taxa de polens viáveis, maior será a chance de fertilização (SANTOS et al., 2015).

A maior porcentagem de viabilidade encontrada para $T$. Speciosum foi às $22 \mathrm{~h}$ (primeira coleta), $10 \mathrm{~h}$ (flores totalmente abertas) e às $22 \mathrm{~h}$ do dia seguinte, apresentado uma média de viabilidade de $98 \%$. Já às $14 \mathrm{~h}$ houve uma redução da viabilidade (94\%) entre os demais horários observados (Tabela 2).

Deste modo, os dados obtidos para a viabilidade do pólen para espécie $T$. Speciosum indicam que os grãos de pólen podem ser coletados a qualquer hora do dia, dentre os observados, uma vez que, a menor média de viabilidade foi de $94 \%$, porém, pelo critério de disponibilidade de pólen nas anteras, em caso de polinizações e hibridações artificiais, essas coletas devem ser realizadas nos primeiros horários da antese, proporcionando uma maior deposição de pólen nos braços estigmáticos.

Os valores obtidos para o intervalo de confiança a $95 \%$, demonstraram que o maior intervalo foi observado às $14 \mathrm{~h}$, apresentando um limite inferior de $90,83 \%$ e superior de $96,77 \%$. O menor intervalo de confiança é às $22 \mathrm{~h}$ (início da avaliação), com limite inferior e superior de $98,57 \%$ e $99,73 \%$, respectivamente. Vale ressaltar que os horários das $22 \mathrm{~h}$ foram os de maior viabilidade polínica, o que justifica 0 menor valor entre os intervalos de confiança (Figura 4).

De acordo com Jesus et al. (2018) quanto maior à viabilidade dos grãos de pólen maior o índice de fertilização e produção de combinações entre alelos distintos. Assim, a alta viabilidade polínica encontrada para T. speciosum, favorece para que as populações mantenham seus níveis de variabilidade, podendo ser utilizados em polinizações artificiais.

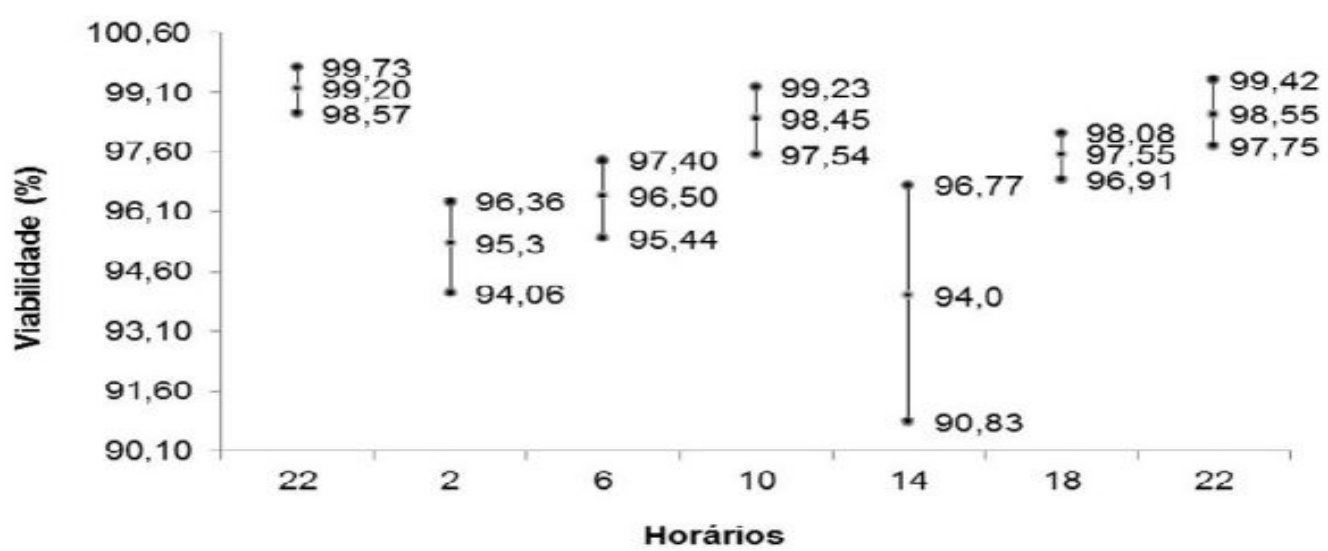

FIGURA 4- Intervalos de confiança a 95\% para os sete horários avaliados em T. speciosum. Fonte: os autores.

\section{Receptividade Estigmática}


A média da receptividade estigmática foi de $75 \%$, sendo os estigmas receptivos em todos os horários analisados (Tabela 3). Portanto, quanto maior período de receptividade do estigma, melhores serão as estratégias a serem utilizadas durante os processos de cruzamento de $T$. speciosum da população do parque $\mathrm{C} / \mathrm{E}$.

TABELA 3- Médias percentuais da receptividade estigmática de $T$. speciosum entre os horários observados por três dias consecutivos.

\begin{tabular}{lcccc}
\hline \multirow{2}{*}{ Horário } & \multicolumn{4}{c}{ Receptividade } \\
\cline { 2 - 5 } & 1 $^{\text {a Avaliação }}$ & $\mathbf{2}^{\text {a }}$ Avaliação & $\mathbf{3}^{\mathbf{a}}$ Avaliação & Média geral \\
\hline 22h00min & $78 \%$ & $78 \%$ & $98 \%$ & $85 \%$ \\
02h00min & $85 \%$ & $100 \%$ & $100 \%$ & $95 \%$ \\
06h00min & $75 \%$ & $95 \%$ & $95 \%$ & $88 \%$ \\
$10 \mathrm{~h} 00 \mathrm{~min}$ & $93 \%$ & $95 \%$ & $95 \%$ & $94 \%$ \\
$14 \mathrm{~h} 00 \mathrm{~min}$ & $83 \%$ & $70 \%$ & $88 \%$ & $80 \%$ \\
$18 \mathrm{~h} 00 \mathrm{~min}$ & $70 \%$ & $80 \%$ & $85 \%$ & $78 \%$ \\
$22 \mathrm{~h} 00 \mathrm{~min}$ & $83 \%$ & $80 \%$ & $80 \%$ & $81 \%$ \\
\hline
\end{tabular}

Constatou-se que às $22 \mathrm{~h}$ (horário inicial) os botões florais já se apresentavam receptivos, com uma média de $85 \%$. Porém, durante a antese às $02 \mathrm{~h}$ e $10 \mathrm{~h}$ (flor aberta) ocorreram os maiores índices de receptividade $(95 \%$ e $94 \%$, respectivamente), observando uma redução na receptividade de $T$. speciosum nos horários das $14 \mathrm{~h}, 18 \mathrm{~h}$ e $22 \mathrm{~h}(80 \%, 78 \%, 81 \%$, respectivamente) (Tabela 3 e Figura 5).

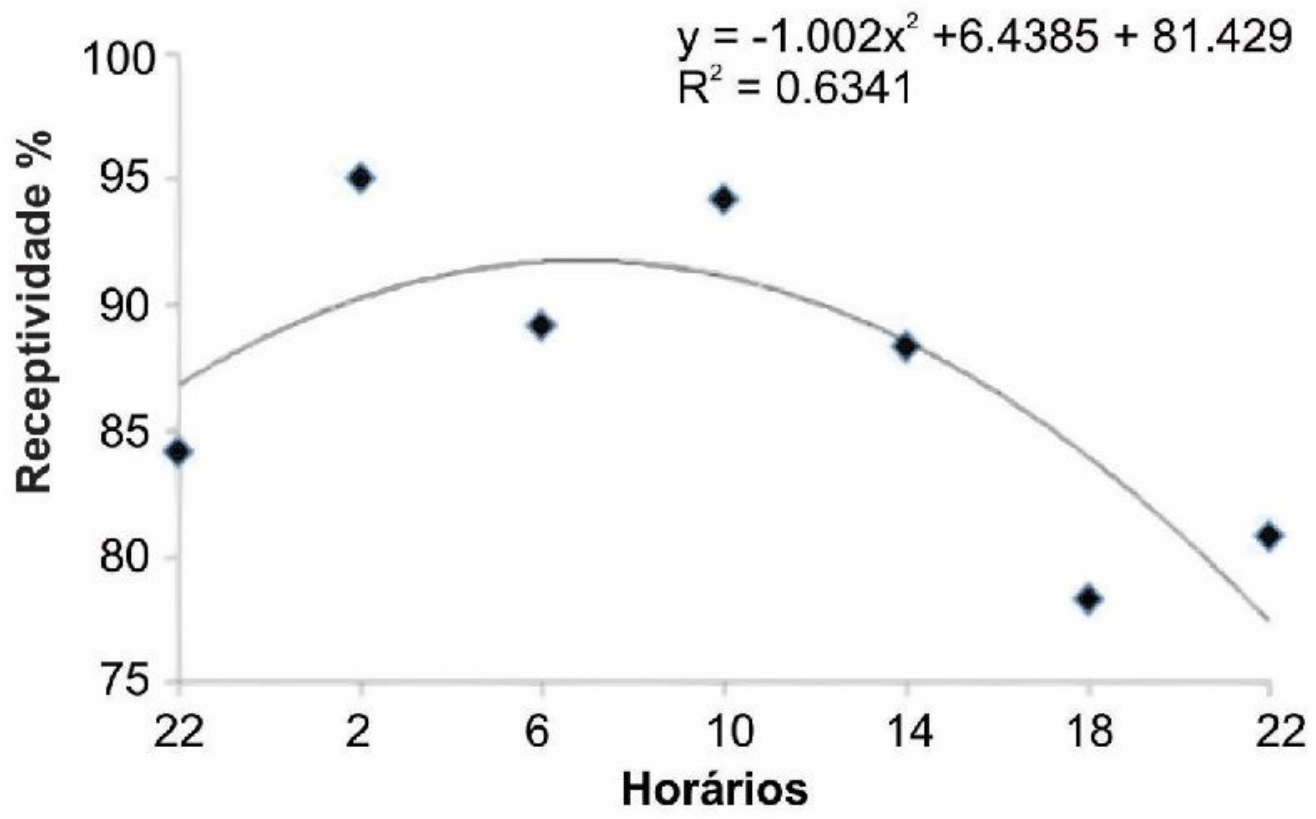

FIGURA 5- Estimativa de estigmas receptivos de $T$. speciosum ao longo de 24 horas de avaliação em setembro de 2014. Fonte: os autores.

Os resultados obtidos por Souza e Venturieri (2010), avaliando a receptividade do estigma de $T$. speciosum, em cinco horários de observação, ENCICLOPÉDIA BIOSFERA, Centro Científico Conhecer - Goiânia, v.16 n.29; p. 287 
corroboram com os desta pesquisa, uma vez que, seus maiores valores de receptividade foram das $06 \mathrm{~h}$ às $10 \mathrm{~h}$.

Arenas-de-Souza (2016) estudando a receptividade estigmática de $T$. subincanum encontrou receptividade em botões de florais em pré-entese às $22 \mathrm{~h}$, porém, com menor receptividade estigmática $(49,17 \%)$, sendo o horário de maior receptividade ás $10 \mathrm{~h}(83,33 \%)$. Os resultados obtidos evidenciam que durante 0 período da manhã, em ambos os estudos, é o mais indicado no caso de polinizações controladas para $T$. speciosum e $T$. subincanum. Esses dados poderão auxiliar futuros estudos envolvendo as espécies do gênero Theobroma, pois uma alta taxa de receptividade aumenta o sucesso da fertilização.

\section{CONCLUSÕES}

Theobroma speciosum apresenta alta viabilidade polínica, independente do horário de coleta, com média superior a $94 \%$. Os estigmas foram receptivos durante todo o período de observação, entretanto os maiores percentuais de receptividade foram observados nos horários das $02 \mathrm{~h}$ e $10 \mathrm{~h}$ da manhã, sendo, portanto, recomendado que as polinizações controladas sejam realizadas nesses horários.

\section{REFERÊNCIAS}

ALEXANDER, M.P. Versatile stain for pollen fungi yeast and bacteria. Stain technology, v. 55, n. 1, p. 13-18, 1980. Disponível em: <https://doi.org/10.3109/10520298009067890>. doi: 10.3109/10520298009067890.

ARENAS-DE-SOUZA, M. D.; ROSSI, A. A. B.; VARELLA, T. L.; SILVEIRA, G. F. D.; SOUZA, S. A. Stigmatic receptivity and pollen viability of Theobroma subincanum Mart.: fruit species from the amazon region. Revista Brasileira de Fruticultura, v. 38, $\quad$ n. $4, \quad 2016 . \quad$ Disponível <http://www.scielo.br/scielo.php?script=sci_arttext\&pid=S0100-294520160004002 $01 \& \operatorname{lng}=e n \& t \mid n g=e n>$. doi: 10.1590/0100-29452016757.

CHEN, Y. S.; DAYOD, M.; TAWAN, C. S. Anther Dehiscence, Pollen Viability and Stigma Receptivity Study on Cultivars of Black Pepper (Piper nigrum L.). Pertanika Journal of Tropical Agricultural Science, v. 41, n. 2, 2018. Disponível em: <http://www.pertanika.upm.edu.my/Pertanika\%20PAPERS/JTAS\%20Vol.\%2041\%20 (2)\%20May.\%202018/21\%20JTAS\%20Vol\%2041\%20(2)\%20May\%202018_JTAS1282-2017_pg801-814.pdf>.

CRISPIM, J. G.; RÊGO, E. R.; RÊGO, M. M.; NASCIMENTO, N. F. F.; BARROSO, P. A. Stigma receptivity and anther dehiscence in ornamental pepper. Horticultura Brasileira, v. 35, n. 4, p. 609-612, 2017. Disponível em: < http://www.scielo.br/scielo.php?script=sci_arttext\&pid=S0102-053620170004006 09\&lng=en\&tlng=en>. doi: 10.1590/S0102-053620170421.

CRUZ, C. D. GENES - a software package for analysis in experimental statistics and quantitative genetics. Acta Scientiarum. v.35, n.3, p.271-276, 2013. Disponível em: $<$ http://www.scielo.br/scielo.php?script=sci_abstract\&pid=S1807-86212013000300 001\&lng=en\&nrm=iso\&tlng=pt>. doi: 10.4025/actasciagron.v35i3.21251.

DARDENGO, J. D. F. E.; ROSSI, A. A. B.; DA SILVA, B. M.; DA SILVA, I. V.; DA SILVA, C. J. et al. Diversity and spatial genetic structure of a natural population of 
Theobroma speciosum (Malvaceae) in the Brazilian Amazon. Revista de biologia tropical, v. 64, n. 3, 2016. Disponível em: < https://revistas.ucr.ac.cr/index.php/rbt/article/view/21461/25869>. doi: 10.15517/RBT.V64I3.21461.

ESTEVES, G. Theobroma. Lista de Espécies da Flora do Brasil. Jardim Botânico do Rio de Janeiro. Disponível em: <http://www.floradobrasil.jbrj.gov.br/jabot/floradobrasil/FB23617>. Acesso em: 20 Dez. 2014.

FERREIRA, D. F. SISVAR: um programa para análises e ensino de estatística. Revista Symposium, v. 6, p. 36-41, 2008. Disponível em: < http://www.dex.ufla.br/ danielff/meusarquivospdf/art63.pdf>.

FLORA DO BRASIL 2020 em construção. Jardim Botânico do Rio de Janeiro. Disponível em: <http://floradobrasil.jbrj.gov.br/reflora/floradobrasil/FB23622>. Acesso em: 27 Mar. 2019.

GIUSTINA, L. D.; LUZ, L. N.; VIEIRA, F. S.; ROSSI, F. S.; SOARES-LOPES, C. R. A.; PEREIRA, T. N. S.; ROSSI, A. A. B. Population structure and genetic diversity in natural populations of Theobroma speciosum Willd. Ex Spreng (Malvaceae). Genetics and molecular Research, v. 13, n. 2, p. 3510-3519, 2014. Disponível em: <https://pdfs.semanticscholar.org/15a3/1b1c483b172b65e4ec8d59b2d1f2fe4dbb30.p df>. doi: 10.4238/2014.February.14.5.

HISTER, C. A. L.; TEDESCO, S. B. Estimativa da viabilidade polínica de araçazeiro (Psidium cattleianum Sabine) através de distintos métodos de coloração. Revista Brasileira de Plantas Medicinais, v. 18, n. 1, p. 135-141, 2016. Disponível em: < http://www.scielo.br/scielo.php?pid=S1516-05722016000100135\&script=sci_ abstract\&tlng=pt>. doi: 10.1590/1983-084X/15_081.

JESUS, L. D. G. A.; TAVARES, L. R.; DA COSTA GOMES, M. F.; DOS SANTOS VALENTE, S. E.; GOMES, R. L. F. et al. Eficiência de testes colorimétricos para determinação da viabilidade do pólen em acessos de feijão-fava (Phaseolus lunatus L). Revista Brasileira de Agropecuária Sustentável, v. 8, n. 1, p. 59-64. 2018. Disponível em: https://periodicos.ufv.br/ojs/rbas/article/view/2979.

LIMA, B. F. S.; HERRMANN, F.; PARISOTTO, D. C.; NASCIMENTO, L. S. D. S.; KARSBURG, I. V. Índice meiótico e viabilidade polínica de Apeiba tibourbou Aubl. Agrarian Academy, Centro Científico Conhecer, v. 5, n. 9, p. 275-282, 2018. Disponível em: <http://www.conhecer.org.br/Agrarian\%20Academy/2018a/indice\%20meiotico.pdf>. doi: 10.18677/Agrarian_Academy_2018a27.

LORENZI, H. Árvores brasileiras: manual de identificação e cultivo de plantas arbóreas nativas do Brasil. Nova Odessa: Instituto Plantarum de Estudos da Flora, 1998, $352 \mathrm{p}$.

LORENZI, H. Árvores brasileiras: manual de identificação e cultivo de plantas arbóreas nativas do Brasil. Nova Odessa: Instituto Plantarum, 2009. 384 p. 
MORENO, E. C.; TIAGO, A. V.; ROSSI, F. S.; ROSSI, A. A. B. Biologia floral, morfometria e viabilidade polínica do maracujá-amarelo (Passiflora edulis Sims $\mathrm{f}$. Flavicarpa Degener). Enciclopédia Biosfera, Centro Científico Conhecer, v.11 n.21; p. 2094-2104, 2015. Disponível em: <http://www.conhecer.org.br/enciclop/2015b/biologicas/biologia\%20floral.pdf>.

OTÁROLA, M. F.; ROCCA, M. A. Flores no tempo: a floração como fase da fenologia reprodutiva. In: RECH, A. R.; AGOSTINI, K.; OLIVEIRA, P. E.; MACHADO, I. C. Biologia da polinização. 2014, p. 115-126.

QUEIROZ, T. N.; SILVA, N. T.; ALVES, S. M.; NASCIMENTO, P. N.; KARSBURG, I. V. Uso de diferentes corantes para a estimativa da viabilidade polínica e caracterização dos grãos de polens de sorgo granífero. Agrarian academy, Centro Científico Conhecer, v.5, n.9, p. 327- 333, $2018 . \quad$ Disponível em:<http://www.conhecer.org.br/Agrarian\%20Academy/2018a/uso\%20de\%20diferen tes.pdf>. doi: 10.18677/Agrarian_Academy_2018a32.

RAMOS, L. P. N.; ANDRÉ, V. L. S.; MELLO, V. S.; DAMASIO, J. F.; KARSBURG, I. V. Estudo da viabilidade polínica de Myrciaria cauliflora (Mart.) O. Berg. por meio de distintos métodos de coloração. Agrarian Academy, Centro Científico Conhecer, v.4, n.8; p. 143-152, $2017 . \quad$ Disponível em: <http://www.conhecer.org.br/Agrarian\%20Academy/2017b/estudo\%20da\%20viabilid ade.pdf>. doi: 10.18677/Agrarian_Academy_2017b15.

SANTOS, T. A dos; TIAGO, P. V.; SCHMITT, K. F. M.; MARTINS, K. C.; ROSSI, A. A. B. Viabilidade polínica em Bertholletia excelsa Bonpl. (Lecythidaceae) baseada em diferentes testes colorimétricos. Enciclopédia Biosfera, Centro científico conhecer, v.11, n.22, 2015. Disponível em: < http://www.conhecer.org.br/Agrarian\%20Academy/2018a/uso\%20de\%20diferentes.p df>. doi: 10.18677/Enciclopedia_Biosfera_2015_030.

SILVA, B. M.; ROSSI, A. A. B.; DARDENGO, J. F. E.; SILVA, C. R.; SILVA, I. V. et al. Genetic structure of natural populations of Theobroma in the Juruena National Park, Mato Grosso State, Brazil. Genetics and Molecular Research, v. 14, n. 3, p. 1036510375, 2015. Disponível em: < http://www.funpecrp.com.br/gmr/year2015/vol143/pdf/gmr5689.pdf>. doi: DOI http://dx.doi.org/10.4238/2015.September.1.3.

SOARES, T. L.; SOUZA, E. H.; COSTA, M. A. P. C.; SILVA, S. O.; SANTOSSEREJO, J. A. Viability of pollen grains of tetraploid banana. Bragantia, v. 75, p. 30, 2016. Disponível em: <http://dx.doi.org/10.1590/1678-4499.328>. doi: http://dx.doi.org/10.1590/1678-4499.328.

SOUZA, J. G.; NASCIMENTO, V. T.; DE MENEZES RIBAS, J. Biologia floral e reprodutiva de Corchorus hirtus L.(Malvaceae) uma espécie de mata seca do Cerrado do Oeste da Bahia. Gaia Scientia, v. 12, n. 1, 2018. Disponível em: <http://www.periodicos.ufpb.br/index.php/gaia/article/viewFile/32651/19841>.

SOUZA, M. S.; VENTURIERI, A. G. Floral Biology of Cacauhy (Theobroma speciosum - Malvaceae). Brazilian Archives of Biologyand Technology, v. 53, n. 
4, p. 861-872, 2010. Disponível em: http://dx.doi.org/10.1590/S151689132010000400016. doi: 10.1590/S1516-89132010000400016.

SOUZA, S. P.; VENTURIERI, G. A. Floral phenologyof cacau-cabeça-de-urubu (Theobroma obovatum). In: Venturieri, G. A. Biologia aplicada à domesticação de fruteiras amazônicas do gênero Theobroma - Primeiro relatório: $\mathrm{CNPq} /$ Programa de Trópico Úmido, Belém, PA, Brasil, 1998, p.105.

STIEHL-ALVES, E. M.; MARTINS, P. M. Biologia reprodutiva de Acacia mearnsii de Wild.: Receptividade de estigmas. Revista Árvore, v. 32, n. 4, p. 609-616, 2008. Disponível em: <http://www.redalyc.org/articulo.oa?id=48813385001>.

TAKEHANA, C. L. I.; OHASHI, T. S.; JARDIM, M. A. G.; SANTOS, J. M. Biologia floral e visitantes florais de Anacardium giganteum W. Hancock ex. Engl. (Anacardiaceae) no município de Bragança, Pará. Revista de Ciências Agrárias Amazonian Journal of Agricultural and Environmental Sciences, v. 56, n. 3, p. 202-211, 2013. doi: http://dx.doi.org/10.4322/rca.2013.030.

VARELLA, T. L.; ROSSI, A. A. B.; DE SOUZA, M. D. A.; DA SILVEIRA, G. F.; COCHEV, J. S. et al. Estrutura populacional e distribuição espacial de Theobroma speciosum Willd. Ex Spreng no norte do estado de Mato Grosso. Ciência Florestal, v. $28, \quad$ n. $1, \quad$ p. 115-126, 2018. Disponível em: <http://www.scielo.br/pdf/cflo/v28n1/1980-5098-cflo-28-01-115.pdf>. http://dx.doi.org/10.5902/1980509831589. 